\title{
As reflexões do professor como agente de letramento na escrita do gênero diário
}

\author{
Cecília Barbosa Lins Aroucha \\ Universidade Federal de Alagoas \\ ceciliaaroucha@gmail.com \\ Lúcia de Fátima Santos \\ Universidade Federal de Alagoas \\ lfsmar@hotmail.com
}

\section{Resumo}

Neste artigo temos como objetivo discutir como uma professora analisa sua prática pedagógica em anotações do gênero discursivo diário. Trata-se de resultados obtidos em uma pesquisa de doutorado, desenvolvida em práticas de letramento de um Instituto Federal. A análise fundamenta-se em estudos do Letramento conjugados com abordagens do Círculo de Bakhtin. Os dados indicam que as autorreflexões da professora como agente de letramento possibilitaram uma maior compreensão sobre sua própria prática e, por conseguinte, motivaram alterações em sua formação docente, problematizando questões do cotidiano da sala de aula e construindo, conjuntamente com os alunos, alternativas possíveis para dificuldades evidenciadas.

Palavras-chave: Agente de letramento; Formação docente; Gênero diário.

\begin{abstract}
In this article, we discuss how a teacher analyzes her pedagogical practice in notes in the journal discursive genre. These are results obtained in doctoral research, developed in literacy practices of a Federal Institute. Literacy studies combined with Bakhtin Circle approaches are the theoretical bases for the analysis. The data indicate that the teacher's self-reflections as a literacy agent enabled a greater understanding of her practice and, therefore, motivated changes in her teacher training, problematizing issues in the classroom and building, together with the students, possible alternatives for evidenced difficulties
\end{abstract}

Keywords: Literacy agent; Teacher training; journal genre. 
As reflexões do professor como agente de letramento...

\section{Introdução}

Este artigo resulta de uma pesquisa de doutorado que analisou práticas autorreflexivas de uma professora como agente de letramento no Curso Técnico de Computação Gráfica de um Instituto Federal. Na abordagem aqui proposta, temos como objetivo discutir como a professora analisa sua prática pedagógica em anotações no gênero discursivo diário. Trata-se, assim, de dados obtidos em um contexto de ensino de autorreflexão, no qual a professora assume também o lugar de pesquisadora. Para fundamentar nossa análise, recorremos às discussões acerca do letramento do professor associadas aos postulados bakhtinianos sobre a concepção dialógica de linguagem. Inclusive, a produtividade da conjugação entre essas abordagens teóricas confirma-se em outros trabalhos, como Lillis (2003), Kleiman (2007, 2008b, 2014), Fiad (2013).

Em uma discussão que toma como base o letramento no mundo escolar, Kleiman (2014, p.72), ao referir-se à atuação do professor como agente de letramento, afirma que entende como "um agente de letramento (professor, assistente, voluntário) que ame a leitura, que saiba contar histórias, enfim, que alimente o desejo e a curiosidade pela escrita do aluno." Compreendemos que essa atuação acontece de forma responsiva ativa, dialógica, tal como postulam as discussões do Círculo de Bakhtin, como em Bakhtin/Volochinov (2006) e Bakhtin (2011). Sob essa perspectiva, as ações desenvolvidas pelo professor como agente de letramento são embasadas na concepção de linguagem como interação, assim "toda compreensão plena real é ativamente e responsiva e não é senão uma fase inicial e preparatória da resposta (seja qual for a forma em que se dê). O próprio falante está determinado precisamente a essa compreensão ativamente responsiva", conforme Bakhtin (2011, p.272). Sob essa perspectiva, mesmo "uma breve e fragmentária réplica" pressupõe uma posição responsiva dos participantes reais da comunicação discursiva.

\section{0 professor como agente de letramento e sujeito reflexivo}

De acordo com as discussões de Kleiman (2007, p.21), a caracterização do professor como agente de letramento pressupõe a capacidade de construir articulações com base nos interesses apresentados pelos aprendizes, "organizar um grupo ou comunidade para a ação coletiva, 
auxiliar na tomada de decisões sobre determinados cursos de ação, interagir com outros agentes [...] de forma estratégica e modificar e transformar seus planos de ação segundo as necessidades em construção do grupo”. Nesse sentido, compreendemos que, ao adotar essa caracterização, o professor demonstra uma disponibilidade contínua para instaurar espaços de interação com os alunos. Atuar sob essa concepção de linguagem implica também considerar que

toda enunciação efetiva, seja qual for sua forma, contém sempre, com maior ou menor nitidez, a indicação de um acordo ou de um desacordo com alguma coisa. Os contextos não estão simplesmente justapostos, como se fossem indiferentes uns aos outros; encontram-se numa situação de interação e de conflito tenso e ininterrupto (BAKHTIN/VOLOCHINOV, 2006, p. 109).

Esses acordos ou desacordos instaurados nas enunciações podem ser evidenciados, no contexto escolar, com as possibilidades em que o professor se aproxima dos estudantes e realiza conjuntamente práticas discursivas que motivem a manifestação das opiniões deles, problematizando e ressignificando as práticas letradas das quais participam. Para Kleiman (2006, p. 82), uma das atribuições do professor é promover a realização de "práticas de letramento em contexto escolar", visando à inserção dos alunos, aliada à concepção de agente de letramento. Para isso, há necessidade de ele compreender que a escrita se realiza em interações concretas e propicia ao sujeito questionamentos sobre a realidade que potencializam ações para mudanças sociais. Kleiman (2006) também comenta que a concepção da escrita que preza pela elaboração de competências voltadas para uma linguagem obscura, imprecisa, não dialoga com os modelos que compreendem a aprendizagem da escrita como uma prática discursiva. Então, depreendemos que são imprescindíveis investimentos na formação do professor, a fim de que ele possa orientar a escrita dos estudantes e ajudá-los a modificar a atuação deles na sociedade, através de atividades de escrita que envolvem reflexões, como também a busca por melhorias através de ações de linguagem.

As ações de um professor visando à transformação do seu ambiente correspondem à discussão sobre agente de letramento apresentada por Cunha (2010). Movido por essa proposta de intervir na realidade, ele pode expandir a sua influência a outras pessoas envolvidas com o contexto 
escolar (estudantes, diretor, coordenador, servidores em geral), motivadas pelos interesses e pelas necessidades do grupo. As ações desenvolvidas também propiciam a criação de uma cultura de que todos podem agir pela coletividade. Para isso, acreditamos ser necessária uma maior compreensão sobre o trabalho efetivo do professor, considerando aspectos de sua formação.

Kleiman (2008b) afirma que a capacidade linguístico-enunciativodiscursiva do docente é questionada pela mídia, como também por outras instâncias sociais, que colocam em discussão a formação letrada desse profissional. Nesse sentido, Santos (2007), ao refletir sobre a escrita de professores em formação inicial, atribui ao professor-formador a tarefa de orientar o processo de constituição do futuro professor, para que este supere as dificuldades evidenciadas em seu processo de aprendizagem. Desse modo, nas práticas de escrita vivenciadas pelos professores durante a formação, eles precisam expressar um domínio linguístico-discursivo que lhes permita atuar, efetivamente, como agentes de letramento nas práticas pedagógicas que desenvolverão na educação básica. Porém essa autora, com base em resultados de pesquisa sobre a escrita de alunos de Letras, afirma que

É justamente sobre a ausência de práticas de produção de textos que incidem as maiores críticas dos alunos quando avaliam seu processo de escrita. Além de essas práticas quase inexistirem, os alunos não saem do curso distinguindo uma perspectiva teórica da outra, ou seja, ficam perdidos na grande miscelânea de teorias, incutida por "partidários" de diferentes perspectivas linguísticas e literárias, apresentadas em cada disciplina. (SANTOS, 2007, p.180)

Essas lacunas, na formação dos alunos durante a licenciatura, desencadeiam sérias consequências quando se tornam, efetivamente, professores na educação básica e trazem implicações para sua identidade docente. Desse modo, as práticas de autorreflexão podem constituir-se um caminho promissor para esses professores buscarem alternativas com o intuito de melhorar a formação. Ao abordar sobre professor reflexivo, Zeichner (1993) esclarece que o termo reflexão recebeu várias atribuições internacionalmente e isso acabou desvalorizando-lhe em certa medida, uma vez que esse termo nem sempre compartilha dos mesmos significados. De 
acordo com as discussões que esse autor apresenta, entendemos que, para ele, reflexão está intimamente vinculada à criticidade.

Outra discussão apresentada por Zeichner (1993) refere-se ao fato de que professores que estão fora das universidades e de centros de pesquisa também produzem conhecimento e "ensino de qualidade" (p. 16) e são capazes de "contribuir para uma base codificada de conhecimentos de ensino" (p. 16). Aceitar essa proposição representa um meio de iniciar o reconhecimento dos professores como geradores efetivos de aprendizado. Do contrário, segundo esse autor, os professores apenas recebem as normas e as aplicam, o que nem sempre poderia ser considerado válido.

A respeito do modo como acontece, em geral, a formação de professores, Zeichner (1998, p. 9) afirma que, em seus programas de formação de professores, objetiva proporcionar aos estudantes um ensino devidamente qualificado. Entendemos que essa preocupação deve ser fortemente difundida no meio acadêmico, considerando o papel fundamental dos professores formadores no sentido de orientar e contribuir para a formação dos futuros professores. Esse autor ainda enfatiza que pretende com suas discussões levar os professores a um processo de autocrítica, de reflexão, tanto de modo coletivo quanto isolado sobre o ensino e todas as circunstâncias que delineiam suas ações. Para tanto, discorre a respeito de pontos de vista essenciais para a elaboração de seu posicionamento sobre a ideia de "professor como prático reflexivo" (ZEICHNER, 1993, p. 25), os quais ele tenta associar a esse conceito de docente, quais sejam:

I - A atenção do professor está tanto virada para dentro, para a sua própria prática, como para fora, para as condições sociais nas quais se situa essa prática. II - A tendência democrática e emancipatória e a importância dada às decisões do professor quanto a questões que levam a situações de desigualdade e injustiça dentro da sala de aula. III - Compromisso com a reflexão enquanto prática social (ZEICHNER, 1993, p. 25-6).

O primeiro princípio defendido pelo autor preconiza que o professor deve concentrar-se em si, mas também nas condições sociais exteriores onde a prática se realiza. Ou seja, o professor não pode se isolar dos acontecimentos que ocorrem em sociedade, pois eles protagonizam um 
papel importante no que diz respeito à constituição dos sujeitos com os quais ele convive, incluindo a si mesmo nesse rol de sujeitos de linguagem.

O segundo princípio consiste em reconhecer "o caráter fundamentalmente político de tudo o que os professores fazem" (ZEICHNER, 1993, p. 26) no sentido de considerar questões éticas, sociais e raciais que surgem no contexto específico da instituição de ensino e abrir espaço para que elas sejam debatidas, tendo em vista que a sala de aula é um local democrático que viabiliza o desenvolvimento de discussões e de argumentações. O terceiro princípio embasa-se no "compromisso com a reflexão enquanto prática social” (ZEICHNER, 1993, p. 26), aspirando a um crescimento mútuo dos professores e transformações na sociedade e na instituição de ensino, que, por sua vez, levam a mudanças sociais e institucionais.

Zeichner (1998) também ressalta a importância de fazer ecoar a voz dos estudantes, de seus pais e da sociedade, ao propor que se leve para a sala de aula os conhecimentos produzidos pelos estudantes. Em suas pesquisas, ele percebeu que falta a muitos pesquisadores aproveitar esse conhecimento de fato, fazendo uso real dele. Sendo assim, podemos entender que, atuando dessa maneira, o professor pesquisador confere credibilidade ao que o estudante constrói, tornando possível o surgimento de um diálogo maior entre ambos, promovendo mudanças nas aulas, no contexto da instituição de ensino e, por sua vez, nos sujeitos que frequentam esse espaço, ensejando a construção processual do conhecimento de um modo muito mais produtivo, que não se resuma somente ao local físico da instituição.

Acreditamos que os princípios apontados pelo referido autor têm correspondência com a perspectiva de letramento, pois indicam uma conduta reflexiva do professor no que diz respeito a sua atuação em sala de aula, provido de práticas sociais de linguagem comprometidas com a construção do conhecimento do estudante e, igualmente, com o crescimento profissional do docente, visando transformar o ambiente onde se realizam essas práticas. Nos termos bakhtinianos, professores e alunos precisam assumir-se como sujeitos responsivos e ativos, participantes de práticas concretas de interação, para responderem adequadamente a esses princípios. Esse é um aspecto fundamental a ser considerado na análise sobre a prática docente da professora em foco. 


\section{A prática docente da professora}

Os dados analisados são um recorte de um amplo corpus, produzido no período de fevereiro a junho de 2017, durante as aulas de Língua Portuguesa Instrumental para uma turma do Curso Técnico Subsequente de Computação Gráfica de um Instituto Federal, em um contexto em que a professora, ao desenvolver sua pesquisa de doutorado, construía reflexões sobre sua prática pedagógica em diários, a fim de ampliar seu conhecimento sobre seu fazer docente e buscar alternativas para melhorar a sua formação. Foram analisadas as anotações em quatorze diários e também as transcrições de dez horas de gravações em áudio das aulas. Ao decidir transformar seu trabalho docente em objeto de pesquisa, assumiu simultaneamente o papel de professora e pesquisadora, observando se as orientações adotadas durante as aulas correspondiam à caracterização de agente de letramento. No decorrer de todo trabalho desenvolvido, ela teve a colaboração da professora-orientadora da tese no planejamento das aulas, como também na análise dos dados da pesquisa. Porém a professoraorientadora não participou das aulas.

No recorte dos dados que selecionamos como objeto de análise neste artigo, apenas consideramos os registros dos diários e excertos de transcrições de aulas. Os diários foram produzidos após a realização de cada aula, e as autorreflexões foram embasadas nas considerações de Zeichner (1993). Em diferentes momentos observados nesse recorte, a prática da professora em sala de aula corresponde à atuação de agente de letramento, como ilustra o diário no qual ela relata que discutiu o planejamento das aulas com os alunos e incentivou para que eles apresentassem sugestões:

Excerto 1. Diário da professora do dia 09/02/2017

Falei de alguns assuntos que poderíamos abordar nas aulas. Além de falar de gêneros que poderíamos produzir, perguntei a eles quais assuntos eles queriam estudar, advertindo que nem tudo poderia ser modificado, porque eu precisaria considerar a ementa, mas que poderia fazer adaptações no meu planejamento [...]. Pedi que, na apresentação de cada um, dissessem de onde eram, quais eram suas preferências por leitura e escrita e quais eram suas maiores dificuldades em Língua Portuguesa. Senti que os estudantes gostaram dessa aproximação inicial, mas percebi que, a princípio, muitos ficaram inibidos de se apresentar, e aos 
poucos, o clima foi ficando mais descontraído, e eles entenderam como era importante vivenciarmos aquele momento. Muitos alegaram dificuldades com questões de gramática, com as regras, com a pontuação e eu disse-lhes que isso seria visto à medida que fôssemos desenvolvendo as aulas, a partir do contato com os textos e com os colegas.

Com base nessas declarações, depreendemos que a professorapesquisadora, ao explicitar que deseja conhecer a realidade dos estudantes e entrar em acordo com eles para inserir algum gênero ou tema que eles sugeriram, demonstra uma conduta correspondente com a perspectiva de letramento que considera como ponto essencial do planejamento as ações. Para Kleiman (2007, p. 17), "O professor assume, nesse caso, um lugar no sistema educacional como profissional que decide sobre um curso de ação com base na observação, análise e diagnóstico da situação". Essa é a orientação que a professora-pesquisadora demonstra adotar quando apresenta pontos do programa e pergunta a apreciação deles, solicitando sugestões ("perguntei a eles quais assuntos eles queriam estudar, advertindo que nem tudo poderia ser modificado, porque eu precisaria considerar a ementa, mas que poderia fazer adaptações no meu planejamento"), como também quando deseja saber dados sobre a identidade e interesses deles ("Pedi que, na apresentação de cada um, dissessem de onde eram, quais eram suas preferências por leitura e escrita e quais eram suas maiores dificuldades em Língua Portuguesa"). Além de atender aos objetivos dos estudos do letramento acerca da formação do professor (KLEIMAN, 2007, 2008a; e 2008b), a professora-pesquisadora em foco indica filiar-se à concepção de linguagem como interação, conforme propõe o Círculo de Bakhtin. Para Bakhtin/Volochinov (2006), os enunciados proferidos pelos sujeitos provocam as respostas de outros sujeitos em um contexto dialógico, em que "toda enunciação, mesmo na forma imobilizada da escrita, é uma resposta a alguma coisa e é construída como tal," (BAKHTIN/VOLOCHINOV, 2006, p. 99).

Fundamentada nessas concepções, a professora abordou em outra aula a discussão sobre gêneros discursivos e buscou construir uma reflexão com os alunos. Porém, ao contrário do que ela supostamente previu, eles não acataram a orientação adotada por ela. Como expressa no registro do diário, sentiu-se insegura tanto em relação à coleta de dados da pesquisa quanto ao olhar de crítica dos alunos acerca da metodologia adotada. 
Excerto 2. Diário da professora do dia 16/03/2017

Neste dia eu me senti insegura mais de uma vez. A primeira delas ocorreu quando constatei que os estudantes das duas turmas foram para a aula, e eu hesitei se poderia utilizar os dados obtidos nesse dia para a minha pesquisa, uma vez que a turma da manhã não fazia parte dela. (...) A segunda vez que senti a insegurança surgiu logo que comecei a exibir os textos e passei a perguntar a eles quais indícios havia naqueles textos que sugeriam tratar-se de uma informação, de um pedido ou de uma ordem. Não foram poucos os olhares que pareciam criticar-me porque aguardavam a resposta que eu não queria dizer, porque entendia que deveria dialogar com eles e construir as definições a partir do conhecimento que eles estavam partilhando naquela prática social. Quando eu exibia um texto, uns não queriam esperar pela resposta do amigo, ou ainda, olhavam com desdém para o amigo que lia mais lentamente, como se ele não merecesse confiança quanto a sua resposta, uma vez que demorava muito a analisar o texto silenciosamente.

A rejeição dos alunos sobre o modo como ela conduziu a análise de textos acerca da caracterização de diferentes gêneros discursivos gerou um incômodo na professora. Porém, mesmo insegura, sobretudo devido à intolerância dos alunos, ela relata que não cedeu à pressão, como também não agiu autoritariamente, entretanto insistiu em assumir a postura de quem age conforme a perspectiva de letramento e firma suas ações a partir do que foi decidido nas primeiras aulas: desenvolver coletivamente a compreensão e respostas para as atividades, construindo espaços dialógicos. Esse comportamento dos estudantes decorre em parte, provavelmente, do fato de eles estarem acostumados a um modelo de ensino em que o professor frequentemente apresenta as respostas para eles, antes mesmo que comecem a desenvolver um raciocínio, fazer inferências ou construir conhecimentos. Conforme a reflexão da professora-pesquisadora, era essa a postura, supostamente, esperada por alguns deles nessa aula. Porém a expectativa deles foi quebrada quando, em busca de efetivar uma atuação correspondente com a de agente de letramento, instiga-os a construir uma posição, mesmo enfrentando a resistência dos alunos ("Não foram poucos os olhares que pareciam criticar-me porque aguardavam a resposta que eu não queria dizer"). 
A partir das demonstrações de insatisfação dos alunos quando ela não atuou conforme esperavam, a professora compreendeu que nem todos aceitariam de imediato a sua escolha por aulas mais interativas, nas quais refletiriam acerca de sua função social, tal como se prevê uma abordagem na perspectiva do letramento. Todavia, mesmo com a reação dos alunos, ela insistiu, como já dissemos, em promover práticas situadas, permeadas por diálogos para que tivessem voz e fossem ouvidos nas aulas sobre temas e gêneros relacionadas às práticas discursivas vivenciadas por eles. Nesse sentido, Bunzen (2010) assevera que alguns gêneros discursivos, embora não façam parte do ambiente escolar, mas, por corresponderem ao cotidiano dos estudantes, são considerados na discussão em sala de aula e contribuem com o aprendizado dos estudantes. Assim, considerando as respostas pelos alunos a um questionário social, aplicado no início do semestre, a professora escolheu tratar acerca de temas que estivessem amplamente relacionados ao cotidiano e aos interesses deles, como um texto intitulado "Precisamos falar de doenças mentais!", selecionado pela professora com base nas sugestões de temas já discutidos com os alunos.

Quando a professora fazia essas escolhas com base na consulta feita aos alunos, ela atuava como agente de letramento e assumia a perspectiva de letramento que defende como a mais viável para a execução de seu trabalho em sala de aula. Por isso, percebemos a preocupação dela em explicar a atividade a ser realizada, como mostra o trecho transcrito a seguir, no qual também observamos que ela comenta quais aspectos do texto gostaria que eles observassem durante a leitura realizada em voz alta pelos estudantes.

Excerto 3. Trecho da aula do dia 18/05/2017

I.../

P: Aproveitando a questão ainda dos blogs, né, eu fiz uma leitura de dois daqui da sala e peguei os textos e coloquei em uma atividade, então já tou pedindo licença após ter feito, viu, César ${ }^{1}$ ?

C: Ahn

P: Após ter feito, eu tou pedindo licença.

${ }^{1}$ Todos os nomes são fictícios para preservarmos a identidade dos alunos. 
P: Eu peguei seu texto e o texto de Janaína daqui da sala pra gente ver como é que a gente pode olhar a coesão e a coerência. Ele fez uma postagem, e eu peguei uma parte do texto dele e embaralhei os parágrafos, são seis parágrafos. Eu embaralhei e aí vocês vão fazer a leitura agora, tentando fazer com que o texto fique coeso e coerente. Eu não alterei ponto e vírgula, pontuação, nada da pontuação dos textos, nenhuma letra foi adicionada, tá certo? Nada foi mexido. O que eu mexi foi nos parágrafos, tão entendendo? Aí vocês vão ler e vão tentar colocar em ordem, tá bom?

Nesse excerto de uma das aulas, a professora explica aos estudantes o objetivo da atividade a ser desenvolvida que envolvia a leitura de dois textos escritos por eles e postados no blog da turma, porém ela troca a ordem dos parágrafos. Ela também enfatiza que não fez nenhuma alteração nos textos, exceto em relação à ordem dos parágrafos: "eu não alterei ponto e vírgula, pontuação, nada da pontuação dos textos, nenhuma letra foi adicionada, tá certo? nada foi mexido. O que eu mexi foi nos parágrafos, tão entendendo?". Com essa atividade, ela objetivava que eles refletissem a respeito de aspectos da textualidade, como a coesão e a coerência, por isso ela copia os textos que os alunos postaram, mas em outra ordem, para provocar a discussão sobre a coesão e coerência. Convém lembrar que em um momento de retomada da explicação da atividade, a professorapesquisadora esclarece que não fez a correção dos textos porque não estava nos objetivos dela, naquele momento, corrigir gramaticalmente as produções dos estudantes.

Durante o momento das explicações, ela lhes informou também que haveria tempo suficiente para a leitura silenciosa deles e também para uma posterior leitura coletiva, seguida de uma discussão a respeito dos temas dos textos, e continuou a explicar alguns aspectos que gostaria que eles observassem na leitura, como a adequação ou não do título e os marcadores enunciativos que indicam o início do texto, conforme podemos ler no excerto a seguir:

Excerto 4. Trecho da aula do dia 18/05/2017

P: Então a primeira coisa que eu queria que vocês prestassem atenção é para o título, porque o título muitas vezes vai sinalizar para o restante do texto. Ele deveria sinalizar e às vezes não acontece isso aí. Eu quero que vocês vejam e me digam, vejam aí 
o título e me digam se ele tem relação com o que foi escrito: linguagens abstratas no ensino médio. Aí a gente depois vai ver se realmente falou sobre isso no texto, tá certo?/.../

Mediante a leitura dos trechos dessa aula do dia dezoito de maio/2017, observamos que a professora-pesquisadora tem o objetivo de interferir tanto no processo de escrita quanto de leitura. Também ela expressa uma certa ansiedade de explicar a atividade a ser desenvolvida ao repetir a proposta e exigir a resposta imediatamente ("Eu quero que vocês vejam e me digam, vejam aí o título e me digam se ele tem relação com o que foi escrito"), talvez desejando motivar uma efetiva compreensão ativa dos estudantes, ou devido ao receio de os alunos, mais uma vez, rejeitarem a metodologia adotada. Também a ansiedade dela pode ser justificada pelo receio de não obter os dados que deseja produzir para a pesquisa que estava em desenvolvimento. Inclusive, ela antecipa a resposta ao dizer que "Ele [o título] deveria sinalizar e às vezes não acontece isso aí". No diário que escreve sobre essa aula, ela confirma essa ansiedade:

Excerto 5. Trecho do diário da professora do dia $18 / 05 / 2017$

Na aula de hoje, 18/05/2017, eu desenvolvi a seguinte atividade: acessei dois blogs feitos pelos estudantes e copiei seus textos em atividades cujos parágrafos estavam desordenados. Eles tinham que colocar em ordem. Eu estava ansiosa pois não sabia se eles iam gostar da proposta, nem se ia dar certo. Por isso, eu tentei explicar tudinho a eles, mais de uma vez, para que não ficasse dúvida e para garantir que eles entenderam como seria a atividade. [...]

Nessa autorreflexão da professora sobre a ansiedade na orientação da atividade, é importante destacar que ela se mostra engajada sobre o que está propondo aos alunos, buscando possibilidades de interagir com eles e de contribuir com o processo de letramento deles e, consequentemente, com o seu próprio letramento como professora, ampliando e ressignificando a sua formação docente. 


\section{Considerações finais}

As autorreflexões propostas pela professora como agente de letramento possibilitaram uma maior compreensão sobre sua própria prática e, por conseguinte, motivaram alterações em sua formação docente, problematizando questões do cotidiano da sala de aula e construindo, conjuntamente com os alunos, alternativas possíveis para dificuldades evidenciadas. Assim, buscou promover práticas discursivas de leitura e de escrita que levassem a mudanças no ambiente escolar e social dos estudantes, como também em seu processo de formação continuada.

Em alguns diários, ela demonstra sentir dificuldades de como atuar como agente de letramento, vivenciando momentos de oscilação e de incertezas quanto à sua conduta em sala de aula, pois a sua formação majoritariamente aconteceu com orientações diferenciadas da proposta do letramento, concebido como práticas situadas de leitura e de escrita. Embora tivesse convicção de que o letramento ideológico era mais viável e lhe oferecia subsídios para conduzir práticas situadas visando a um melhor aproveitamento dos estudantes, ocorreram-lhe alguns momentos de questionamento e de dúvidas, principalmente após as aulas em que alguns alunos demonstravam resistência às orientações propostas.

A despeito disso, em práticas situadas em que atuou como agente de letramento, a professora construiu espaços de interação com os estudantes, motivando-os a expressar suas compreensões sobre os temas discutidos durante o semestre letivo; temas esses relacionados com a realidade dos estudantes, que propuseram alterações no planejamento, acatadas pela professora. Ela também promoveu práticas situadas nas quais os estudantes tiveram a oportunidade de fazer as reflexões a respeito de temas inseridos no cotidiano geral da sociedade, como violência contra os animais, contra a mulher, mobilidade urbana e de alguns temas inseridos no cotidiano deles enquanto estudantes de Computação Gráfica, como jogos digitais, filmes em versões live-action inspirados em gêneros como mangás e animes, tipicamente da cultura oriental, que hoje estão em plena difusão no ocidente e têm agregado grande valor e alcançado um enorme público ocidental.

Um dado que vale ressaltar na análise realizada é que, no momento em que a professora decidiu assumir o papel de sujeito de pesquisa e colocou-se à disposição para a sua realização, sua opção teve como finalidade realizar mudanças promissoras em sua formação em relação a 
uma perspectiva mais engajada do ensino com as questões da realidade dos estudantes e da sua própria realidade. Para isso, foram expressivas as contribuições dos alunos, mesmo daqueles que demoraram a aceitar as orientações apresentadas por ela. Com todos os alunos, indistintamente, houve interação.

Atuar como agente de letramento em consonância com a perspectiva dialógica de linguagem, conforme o percurso metodológico empreendido pela professora, permitem-nos a compreensão de que o papel do professor não precisa se resumir à sala de aula, deve começar muito antes de sua chegada a esse ambiente. A partir das reflexões de Kleiman (2008b), compreendemos que a elaboração do planejamento, a preparação das aulas, a seleção dos aspectos a serem abordados em cada prática e o modo como eles serão explorados são movimentos que podem gerar mais conhecimento na atuação docente, com repercussões para além da sala de aula. Para isso, os movimentos desencadeados pela escrita em diário contribuíram para que a professora atuasse de modo responsivo sobre o trabalho realizado e ampliasse sua formação como agente de letramento.

\section{Referências}

BAKHTIN, Mikhail. Estética da criação verbal. Tradução de Paulo Bezerra. 6. ed. São Paulo: Martins Fontes, 2011.

/VOLOCHINOV, Valentín Nikoláievitch. Marxismo e filosofia da linguagem: problemas fundamentais do método sociológico na ciência da linguagem. 12 ed. São Paulo: Hucitec, [1929], 2006.

BUNZEN, Clécio. Os significados do letramento escolar como uma prática sociocultural. In: VÓVIO, Claudia; SITO, Luanda; GRANDE, Paula. (Orgs.) Letramentos: rupturas, deslocamentos e repercussões de pesquisas em Linguística Aplicada. Campinas: Mercado de Letras, 2010. p. 99-120.

CUNHA, Rosana. O jornal escolar sob a ótica do ensino de gênero e da formação continuada do professor. In: VÓVIO, Claudia; SITO, Luanda; GRANDE, Paula. (Orgs.) Letramentos: rupturas, deslocamentos e repercussões de pesquisas em Linguística Aplicada. Campinas: Mercado de Letras, 2010. p. 141- 162. 
Cecília Aroucha; Lúcia de Fátima Santos

FIAD, Raquel. Reescrita, dialogismo e etnografia. Linguagem em (Dis)curso, v. 13, p. 463-480, 2013.

KLEIMAN. Ângela. Processos identitários na formação profissional: o professor como agente de letramento. In: CORRÊAA, Manoel Luiz Gonçalves; BOCH, Françoise. (Orgs.) Ensino de língua: representação e letramento. Campinas, Mercado de Letras, 2006. p. 75-91.

. Letramento e suas implicações para o ensino de língua materna. Signo, v. 32, n. 53, p. 1-25, 2007.

- Modelos de letramento e as práticas de alfabetização na escola. In: ___ (Org.) Os significados do letramento: uma nova perspectiva sobre a prática social da escrita. 1. ed. Campinas, SP: Mercado das Letras, [1995] 2008a. p. 15-61.

. Os estudos de letramento e a formação do professor de língua materna. Linguagem em (Dis)curso, v. 8, n. 3, p. 487-517, 2008 b.

. Letramento na contemporaneidade. Bakhtiniana, v. 9, n. 2, p. 72-91, 2014.

LILLIS, Theresa. Student writing as 'academic literacies': drawing on Bakhtin to move from critique to design. Language and Education, v. 17, n. 3, p. 192-207, 2003.

SANTOS, Lúcia de Fátima. Produção de textos na universidade: em busca de atitudes ativas e táticas. 2007. 250 f. Tese (Doutorado em Linguística) Faculdade de Letras, Universidade Federal de Alagoas, Maceió, 2007.

ZEICHNER, Kenneth M. A formação reflexiva de professores: ideias e práticas. Lisboa: Educa, 1993.

. Para além da divisão entre professor-pesquisador e pesquisador acadêmico. In: GERALDI. Corinta Maria Grisolia; FIORENTINI. Dario; PEREIRA. Elisabete M. (Orgs.). Cartografia do trabalho docente: professor(a)-pesquisador(a). Campinas, Mercado de Letras, 1998. p. 207236. 
As reflexões do professor como agente de letramento...

Recebido em: 16/06/2019

Aceito em: 09/02/2020

Title: The reflections of the teacher as an agent of literacy in the writing of the genre diary 